\title{
COMMENTARY
}

\section{Stat5a/b in Prostate Cancer Metastasis}

\author{
Allen C. Gao and Yezi Zhu
}

From the Department of Urology, Comprehensive Cancer Center, University of California Davis, Sacramento, California

Invasion and metastasis are critical hallmarks of cancer progression. ${ }^{1}$ Although the overall survival of patients with localized prostate cancer $(\mathrm{CaP})$ has been significantly increased because of prostate-specific antigen screening and improved treatment modalities, the survival rate for patients who develop metastatic $\mathrm{CaP}$ remains unchanged. ${ }^{2}$ The potential mechanisms of the acquired ability of $\mathrm{CaP}$ cells to invade and to disseminate at distant sites remain largely unknown and represent a challenging problem in metastatic $\mathrm{CaP}$ research. In the current issue of The American Journal of Pathology, Talati et $\mathrm{al}^{3}$ describe a novel mechanism for $S t a t 5 \mathrm{a} / \mathrm{b}$ signaling in promoting metastasis in $\mathrm{CaP}$ in vitro and in vivo.

\section{Stat5a/b in CaP Progression}

Stat proteins are a family of transcription factors that mediate cytokine and growth factor responses. ${ }^{4}$ The $94-\mathrm{kDa}$ Stat5a and $92-\mathrm{kDa}$ Stat5b are highly homologous isoforms that are critical cytoplasmic signaling proteins and nuclear transcriptional factors. ${ }^{5}$ Stat $5 \mathrm{a} / \mathrm{b}$ are phosphorylated and activated by upstream kinases, such as Jak2, in response to different cellular ligands, such as prolactin $(\operatorname{Prl}) .{ }^{6}$ Activated Stat5a/b dimerize and rapidly translocate to the nucleus, where they bind to the $\gamma$-interferon activation sequence element and induce Stat5a/b target genes, including the antiapoptotic protein Bcl-XL and the cell-cycle-mediating protein cyclin $\mathrm{D} 1$, as well as other factors that are critical in cell survival and growth. ${ }^{7}$ Furthermore, activated Stat5a/b regulates $\mathrm{CaP}$ viability, and inhibition of $S t a t 5 a / b$ induces cell apoptotic death of $\mathrm{CaP}$ cells in in vitro and in vivo models.

Evidence suggests that activated $S t a t 5 \mathrm{a} / \mathrm{b}$ is elevated in $>60 \%$ of $\mathrm{CaP}$ metastasis, ${ }^{8}$ implicating a role for Stat $5 \mathrm{a} / \mathrm{b}$ in clinical $\mathrm{CaP}$ progression. Furthermore, Stat5a/b status is used to predict early $\mathrm{CaP}$ recurrence and early $\mathrm{CaP}$-specific death. ${ }^{9}$ Introducing constitutively activated forms of Stat $5 \mathrm{a} / \mathrm{b}$ into CaP DU145 cells increases the formation of lung metastases compared with parental DU145 cells ${ }^{10}$; however, the mechanism(s) remain unknown.
In the current study, Talati et $\mathrm{al}^{3}$ proposed that active Jak2-Stat5a/b signaling induces epithelial-to-mesenchymal transition (EMT) and cancer stem cell (CSC) properties in $\mathrm{CaP}$, processes critical in cancer metastasis. By using different models, they demonstrate that active Stat5a/b induced EMT and CSC markers, and promoted metastasis formation of $\mathrm{CaP}$ cells in vivo. ${ }^{3}$

\section{EMT-Associated Changes in CaP}

EMT is a physiological process by which epithelial cells gain mesenchymal characteristics. EMT is involved in a spectrum of both normal physiology and pathological processes and can be activated during the course of invasion and metastasis of $\mathrm{CaP}$. During EMT, the epithelial cells lose epithelial phenotypes, such as cell polarity and cell-cell adhesion, and instead develop mesenchymal phenotypes, such as increased migration, ability to invade, and disorganized extracellular matrix. ${ }^{11} \mathrm{~A}$ decrease in epithelial biomarkers (eg, E-cadherin and $\beta$-catenin) and an increase in mesenchymal markers (eg, $\mathrm{N}$-cadherin and vimentin) are associated with EMT and tumor invasion. Different signaling pathways have been reported to stimulate EMT in $\mathrm{CaP}$, including the growth factor receptor tyrosine kinaseactivated pathway, ${ }^{12}$ Pten-related pathway, ${ }^{13}$ Wnt, Notch, and Hedgehog signaling pathways. ${ }^{14}$

\section{Jak2-Stat5a/b Signaling Is Critical for Prl Induction of EMT in CaP Cells}

Talati et $\mathrm{al}^{3}$ reported that activation of Stat5a/b by cellular ligand Prl was associated with a decrease in E-cadherin expression and a substantial increase in $\mathrm{N}$-cadherin and

Accepted for publication June 4, 2015.

Disclosures: None declared.

Address correspondence to Allen C. Gao, M.D., Ph.D., Department of Urology, University of California Davis, Sacramento, CA 95817. E-mail: acgao@ucdavis.edu. 
other mesenchymal markers, such as vimentin, fibronectin, and Twist1, in different $\mathrm{CaP}$ cell lines independent of the status of androgen receptor. Jak2 kinase inhibitor AZD1480 and knockdown of Stat5a/b by shRNA in CaP cells blocked the Prl-induced changes in the expression of EMT markers. These results were further validated using different animal models, $\mathrm{CaP}$ xenograft of patient tumors, and patient samples cultured ex vivo.

A significant advantage of this study is the use of CWR22Pc cells, which mimic the clinical course of $\mathrm{CaP}$ patients. Mice bearing CWR22Pc tumors were treated with Stat5a/b signaling inhibitor AZD1480 during both primary growth in the presence of androgens and CRPC growth. Inhibition of Stat5a/b up-regulated E-cadherin expression and down-regulated Twist1 expression in CWR22Pc tumors during different time points. Data confirmed that the Jak2$\mathrm{Stat} 5 \mathrm{a} / \mathrm{b}$ is critical for Prl induction of EMT in CaP cells.

\section{Twist1 Is the Key Mediator of the Stat5a/b-Induced EMT in CaP Cells}

EMT is a crucial process during cancer cell migration and metastasis. Talati et $\mathrm{al}^{3}$ analyzed several critical end points associated with EMT in CaP cells. Use of Boyden chamber assays, epithelial monolayer growth versus anchorageindependent survival of small $\mathrm{CaP}$ cell clusters, and adhesion of $\mathrm{CaP}$ cells to fibronectin confirmed that activated Jak2-Stat5a/b signaling induces EMT markers and is accompanied by the EMT-associated changes in CaP. Talati et $\mathrm{al}^{3}$ further identified Twist 1 as the key mediator of the Stat5a/b-induced EMT in CaP. Twist 1 expression was required for EMT markers and the EMT-associated changes.

\section{EMT Promotes the Induction of CSC Phenotype in CaP Cells}

CSCs are a small subset of stem cell-like cancer cells, which have the capability of self-renewal and differentiation. The CSC theory has received increasing attention recently because preclinical models have provided evidence of CSCs contributing to cancer proliferation, relapse, and metastasis. In addition, CSCs generally have slow growth rates and are resistant to chemotherapy and radiotherapy. ${ }^{11}$ Stem cell markers are up-regulated in $\mathrm{CaP}$ xenografts and mouse $\mathrm{CaP}$ models on androgen-deprivation therapy, ${ }^{15-17}$ suggesting that the CSC subpopulation might contribute to castration resistance progression in CaP. Interestingly, EMT is linked with the acquisition of stem cell-like characteristics under the regulation of many cancer-relevant pathways, such as Wnt, Notch, ${ }^{18}$ and Hedgehog signaling. ${ }^{19}$

Talati et $\mathrm{al}^{3}$ demonstrated that, in CaP cells, EMT promoted the induction of a CSC phenotype. The induction of EMT by activation of Jak2-Stat5a/b signaling was accompanied with increased sphere formation of $\mathrm{CaP}$ cells concurrent with induction of markers associated with cancer stem-like properties, such as CD44, Sox2, and BMI1. The study was next expanded to demonstrate that the Jak2-Stat5a/b axis concomitantly drives a stemness phenotype in the CaP cells, an effect also mediated through induction of BMI1. These observations suggest that BMI1 is critical and is required by the Jak2-Stat5a/b axis to promote stem-like cell properties in $\mathrm{CaP}$ cells. By using a human $P R L$ knock-in genetically engineered mouse model, Talati et $\mathrm{al}^{3}$ demonstrated, for the first time, that the Prl-Jak2-Stat5a/b axis drives CaP lung metastasis, which is accompanied with increased levels of Twist1 and BMI1 in the metastatic sites, which further confirmed the results from the in vitro study.

\section{Conclusions}

The current work ${ }^{3}$ suggests that Stat5a/b instigates EMT through inducing the expression of Twist 1 . The induction of BMI1 by active Stat5a/b is also through Twist 1 suppression, which leads to induction of the CSC phenotype. Results from Talati et $\mathrm{al}^{3}$ provide an important piece of evidence for the link between EMT and cancer stem-like properties in $\mathrm{CaP}$. This study also reports, for the first time, that Stat5a/binduced Twist1 plays an important role in EMT and the induction of cancer stem-like property in $\mathrm{CaP}$, both of which increase the metastatic capability of $\mathrm{CaP}$ cells to the lungs of mice. Further studies are needed to understand the mechanisms of regulation of Twist 1 expression by Stat5a/b. Such findings, with the development of pharmacological inhibitors of the Jak2-Stat5a/b-Twist1-BMI1 signaling axis, may present a novel and effective therapeutic strategy to prevent metastasis and dissemination of $\mathrm{CaP}$.

\section{References}

1. Hanahan D, Weinberg RA: Hallmarks of cancer: the next generation. Cell 2011, 144:646-674

2. Wu JN, Fish KM, Evans CP, deVere White RW, Dall'Era MA: No improvement noted in overall or cause-specific survival for men presenting with metastatic prostate cancer over a 20 -year period. Cancer 2014, 120:818-823

3. Talati PG, Gu L, Ellsworth EM, Girondo MA, Trerotola M, Hoang DT, Leiby B, Dagvadorj A, McCue PA, Lallas CD, Trabulsi EJ, Gomella L, Aplin AE, Languino L, Fatatis A, Rui H, Nevalainen MT: Jak2-Stat5a/b signaling induces epithelial-tomesenchymal transition and stem-like cell properties in prostate cancer. Am J Pathol 2015, 185:2505-2522

4. Ihle JN: The Stat family in cytokine signaling. Curr Opin Cell Bio 2001, 13:211-217

5. Liu X, Robinson GW, Gouilleux F, Groner B, Hennighausen L: Cloning and expression of Stat5 and an additional homologue (Stat5b) involved in prolactin signal transduction in mouse mammary tissue. Proc Natl Acad Sci U S A 1995, 92:8831-8835

6. Goffin V, Hoang DT, Bogorad RL, Nevalainen MT: Prolactin regulation of the prostate gland: a female player in a male game. Nat Rev Urol 2011, 8:597-607

7. de Groot RP, Raaijmakers JAM, Lammers JWJ, Koenderman L: STAT5-dependent cyclinD1 and Bcl-xL expression in Bcr-Abltransformed cells. Mol Cell Biol Res Commun 2000, 3:299-305

8. Haddad BR, Gu L, Mirtti T, Dagvadorj A, Vogiatzi P, Hoang DT, Bajaj R, Leiby B, Ellsworth E, Blackmon S, Ruiz C, Curtis M, 
Fortina P, Ertel A, Liu C, Rui H, Visakorpi T, Bubendorf L, Lallas CD, Trabulsi EJ, McCue P, Gomella L, Nevalainen MT: STAT5A/B gene locus undergoes amplification during human prostate cancer progression. Am J Pathol 2013, 182:2264-2275

9. Mirtti T, Leiby BE, Abdulghani J, Aaltonen E, Pavela M, Mamtani A, Alanen K, Egevad L, Granfors T, Josefsson A, Stattin P, Bergh A, Nevalainen MT: Nuclear Stat5a/b predicts early recurrence and prostate cancer-specific death in patients treated by radical prostatectomy. Hum Pathol 2013, 44:310-319

10. Gu L, Vogiatzi P, Puhr M, Dagvadorj A, Lutz J, Ryder A, Addya S, Fortina P, Cooper C, Leiby B, Dasgupta A, Hyslop T, Bubendorf L, Alanen K, Mirtti T, Nevalainen MT: Stat5 promotes metastatic behavior of human prostate cancer cells in vitro and in vivo. Endocr Relat Cancer 2010, 17:481-493

11. Li P, Yang R, Gao WQ: Contributions of epithelial-mesenchymal transition and cancer stem cells to the development of castration resistance of prostate cancer. Mol Cancer 2014, 13:55

12. Gan Y, Shi C, Inge L, Hibner M, Balducci J, Huang Y: Differential roles of ERK and Akt pathways in regulation of EGFR-mediated signaling and motility in prostate cancer cells. Oncogene 2010, 29:4947-4958

13. Mulholland DJ, Kobayashi N, Ruscetti M, Zhi A, Tran LM, Huang J, Gleave M, Wu H: Pten loss and RAS/MAPK activation cooperate to promote EMT and metastasis initiated from prostate cancer stem/progenitor cells. Cancer Res 2012, 72:1878-1889

14. Lamouille S, Xu J, Derynck R: Molecular mechanisms of epithelial-mesenchymal transition. Nat Rev Mol Cell Biol 2014, 15:178-196

15. Seiler D, Zheng J, Liu G, Wang S, Yamashiro J, Reiter RE, Huang J, Zeng G: Enrichment of putative prostate cancer stem cells after androgen deprivation: upregulation of pluripotency transactivators concurs with resistance to androgen deprivation in $\mathrm{LNCaP}$ cell lines. Prostate 2013, 73:1378-1390

16. Tang Y, Hamburger AW, Wang L, Khan MA, Hussain A: Androgen deprivation and stem cell markers in prostate cancers. Int J Clin Exp Pathol 2010, 3:128-138

17. Germann M, Wetterwald A, Guzman-Ramirez N, van der Pluijm G, Culig Z, Cecchini MG, Williams ED, Thalmann GN: Stem-like cells with luminal progenitor phenotype survive castration in human prostate cancer. Stem Cells 2012, 30:1076-1086

18. Espinoza I, Miele L: Deadly crosstalk: notch signaling at the intersection of EMT and cancer stem cells. Cancer Lett 2013, 341:41-45

19. Takebe N, Miele L, Harris PJ, Jeong W, Bando H, Kahn M, Yang SX, Ivy SP: Targeting Notch, Hedgehog, and Wnt pathways in cancer stem cells: clinical update. Nat Rev Clin Oncol 2015, [Epub ahead of print] doi:10.1038/nrclinonc.2015.61 